\title{
PRODUÇÃO DE CARNE EM OVINOS DE CINCO GENÓTIPOS. 6. DESENVOLVIMENTO RELATIVO
}

\author{
MEAT PRODUCTION IN FIVE LAMBS BREEDS. \\ 6. RELATIVE DEVELOPMENT
}

\author{
Ana Paula Roque ${ }^{1}$ José Carlos da Silveira Osório ${ }^{2}$ Pedro Osório Jardim ${ }^{3}$ \\ Nelson Manzoni de Oliveira ${ }^{4}$ Maria Teresa Moreira Osório ${ }^{5}$
}

\section{RESUMO}

O presente estudo objetivou verificar o desenvolvimento relativo dos componentes do peso vivo, da composição regional da carcaça e da composição tecidual da paleta e do quarto em cordeiros das racas Merino Australiano, Ideal, Corriedale, Romney Marsh e Texel. O trabalho foi realizado no Centro de Pesquisa de Pecuária dos Campos Sulbrasileiros (CPPSULEMBRAPA) em Bagé/RS. Foram utilizados 50 cordeiros, sendo 10 de cada uma das raças, nascidos e criados até o desmame (10 semanas) em campo nativo. A partir do desmame, foram suplementados (200g/cab/dia) com uma ração contendo $17 \%$ de PB e $75 \%$ de NDT, oferecida em regime de confinamento até uma semana pós-desmame e a campo até o abate aos 7,5 meses de idade. O estudo do desenvolvimento relativo realizou-se mediante o modelo da equação exponencial: $Y=a . x^{b}$. O desenvolvimento relativo dos componentes do peso vivo, da composição regional e tecidual dos cordeiros sofreu influência dos genótipos. As raças Merino Australiano, Romney Marsh e Texel, mais pesadas ao abate, apresentaram maior rendimento de carcaça, mas nas raças Ideal e Corriedale, o rendimento de carcaça quente foi semelhante ao do peso vivo. Os componentes do peso vivo nos diferentes genótipos apresentaram-se isogônicos (não significativos), com exceção da cabeça, na raça Romney Marsh e Texel, que apresentou um desenvolvimento precoce e o baço, que na raça Merino Australiano, foi tardio. A região do pescoço, nas raças Corriedale e Romney Marsh, apresentou um desenvolvimento precoce, considerando-se a carcaça fria, e o costilhar na raça Romney Marsh mostrou-se tardio. Os outros cortes apresentaram um desenvolvimento semelhante ao da carcaça fria em todos os genótipos estudados. Com base nos resultados, pode-se afirmar que o peso de abate e das diferentes regiões da carcaça em cordeiros depende do genótipo.

Palavras-chave: alometria, carcaça, componentes do peso vivo, composição tecidual, cordeiro, regiões corporais.

\section{SUMMARY}

The aim of the present work was to study the relative development of liveweight components, regional composition and tissue composition of shoulder and hindquarter in Australian Merino, Polwarth, Corriedale, Romney Marsh and Texel lamb. The study was carried out at the Centro de Pesquisa de Pecuária dos Campos Sulbrasileiros of EMBRAPA (CPPSUL/EMBRAPA), located in Bagé, state of Rio Grande do Sul, Brazil. Fifty lambs, ten of each breed, were used, born and raised up to weaning (10 weeks) on native pasture. After weaning, they were fed with a concentrate (200g/lamb/day), containing $17 \%$ of crude protein and $75 \%$ of dry matter basis, which was offered in confinement until one week. After this, they were put onto paddoks and slaughtered at 7.5 months of age. The study on the relative development of liveweight was done by using the equation: $Y=a$ . $x^{b}$. The genotype had an effect on the relative development of liveweight components, and both regional composition and tissue composition. By increasing the liveweight, there was proportional increase in the hot carcass weight in Australian Merino, Romney Marsh and Texel breeds. In Polwarths and Corriedales, the development of both traits was similar. The liveweight components in all genotypes were non significant with exception of head in Romney Marsh and Texel lambs, which showed a late development, and of spleen in Australian Merino lambs, which showed a late development. Related to cold carcass, the neck region had an early development in Corriedale and Romney Marsh lambs, while the rack was late in Romney Marsh lambs. Other cuts showed a similar development in all genotypes. Based on the results of this work, it can be stated that the slaughtery weight of lambs is influenced by genotype.

Key words: allometric growth, body parts, carcass, lambs, live weight components, tissue composition.

\footnotetext{
${ }^{1}$ Zootecnista, aluno do curso de Pós-graduação em Zootecnia, Universidade Federal de Pelotas (UFPel), Faculdade de Agronomia Eliseu Maciel (FAEM), Caixa Postal 354, 96010-900 - Pelotas, RS. e-mail: jcosorio@ufpel.tche.br. Autor para correspondência.

${ }^{2}$ Médico Veterinário, Doutor, Professor Titular, Bolsista do CNPq, UFPel, FAEM, Zootecnia.

${ }^{3}$ Médico Veterinário, Mestre, Professor Adjunto, UFPel, FAEM, Zootecnia.

${ }^{4}$ Médico Veterinário, Mestre, PhD., Pesquisador EMBRAPA (CPPSUL) - Bagé/RS.

${ }^{5}$ Médico Veterinário, Doutor, Professor Adjunto, UFPel, FAEM, Zootecnia.
} 


\section{INTRODUÇÃO}

O crescimento e o desenvolvimento são fenômenos básicos para a produção de carne e estão estreitamente relacionados. Segundo BLACK (1989), o crescimento baseia-se na multiplicação celular (hiperplasia) e no aumento de tamanho das células (hipertrofia).

O estudo comparativo do crescimento nas diferentes raças baseia-se no grau de maturidade do animal. Para BUTTERFIELD (1988), a maturidade é o estado de equilíbrio anatômico alcançado quando o animal parou de crescer. Quanto mais o animal avança para a maturidade, menores são os incrementos de peso vivo em qualquer intervalo de tempo (THOMPSON \& PARKS, 1983). O conhecimento do caminho que segue um animal durante seu desenvolvimento até adquirir a maturidade é importante, uma vez que o valor dos animais de carne depende das mudanças que se produzem nesse período (PÁLSSON, 1955).

$\mathrm{O}$ peso vivo e o valor de seus componentes variam com a idade, raça e sexo (COLOMER \& ESPEJO, 1971). Igualmente, as diferenças na proporção dos cortes comerciais da carcaça variam em função do peso, raça, sexo e sistema de criação (SAÑUDO, 1980 e LOPEZ SANCHEZ, 1987). A realização dos estudos do crescimento alométrico permite estabelecer o tipo de carcaça ideal que, segundo BUTTERFIELD (1968), será aquela com máxima proporção de músculo, a mínima de osso e uma proporção de gordura exigida pelo mercado a que a carcaça será destinada.

$\mathrm{O}$ presente trabalho tem como objetivo determinar o desenvolvimento relativo dos componentes do peso vivo, da composição regional da carcaça e da composição tecidual da paleta e do quarto em cordeiros das raças Merino Australiano, Ideal, Corriedale, Romney Marsh e Texel.

\section{MATERIAL E MÉTODOS}

O trabalho foi realizado no Centro de Pesquisa de Pecuária dos Campos Sulbrasileiros (CPPSUL-EMBRAPA), em Bagé/RS. Foram utilizados 50 cordeiros, sendo 10 de cada uma das cinco raças (Merino Australiano, Ideal, Corriedale, Romney Marsh e Texel). Os cordeiros foram criados até o desmame (10 semanas) em campo nativo com predominância de Paspalum notatum Flügge e Axonopus affinis Chase, com uma lotação de 0,5 animal por hectare. A identificação ocorreu ao nascer e a castração foi aos 30 dias de idade.

A partir do desmame, os cordeiros foram suplementados (200g/cab/dia), com uma ração con- tendo $17 \%$ de PB e $75 \%$ de NDT, formulada a partir de farelo de arroz gordo e desengordurado, capim arroz, sorgo, uréia, farinha de osso, sal mineral e comum. Até uma semana pós-desmame, a ração foi oferecida em regime de confinamento e depois a campo até o abate aos 7,5 meses de idade. Após um jejum de 14 horas, os animais foram pesados e abatidos. Os pesos tomados imediatamente após o abate foram: carcaça quente, cabeça, patas, pelego, vísceras brancas, coração, pulmões com a traquéia, baço e fígado.

Após permanecerem por 14 horas em câmara fria $\left(1^{\circ} \mathrm{C}\right)$, foi anotado o peso das carcaças frias. Na meia carcaça direita, após separação dos cortes, foram realizadas as seguintes aferições: peso do pescoço, da paleta, do costilhar e do quarto. Para a realização da composição tecidual, foram desossados a paleta e o quarto e anotados os pesos de osso, músculo e gordura de cada um deles.

Para avaliação do desenvolvimento relativo utilizou-se a equação exponencial $\mathrm{y}=\mathrm{a} \cdot \mathrm{x}^{\mathrm{b}}$, transformada logaritmicamente em regressão linear (HUXLEY, 1932); sendo que, para obtenção do desenvolvimento relativo dos componentes do peso vivo, foi utilizado: $\mathrm{y}=$ peso da cabeça, das patas, do pelego, das vísceras brancas, do coração, dos pulmões com traquéia, do baço, do fígado e da carcaça quente $\mathrm{e}, \mathrm{x}=$ peso vivo ao sacrifício. Com relação à composição regional: $\mathrm{y}=$ peso do pescoço, da paleta, do costilhar e do quarto e, $\mathrm{x}=$ peso da carcaça fria. Para composição tecidual: $y=$ peso do osso, do músculo e da gordura da paleta e do quarto e, $\mathrm{x}=$ peso da paleta e do quarto. As análises estatísticas descritivas e cálculo dos coeficientes alométricos foram realizados através do pacote estatístico SAS (SAS, 1985). Para verificação da hipótese $b=1$ foi utilizado o teste ' $\mathrm{t}$ ' $(\mathrm{P}<0,05)$.

\section{RESULTADOS E DISCUSSÃO}

Verificou-se (tabela 1) que a carcaça quente nas raças Merino Australiano, Romney Marsh e Texel apresenta coeficientes de alometria heterogônicos $(b \neq 1)$, com desenvolvimento tardio (b > 1) em relação ao peso vivo. Já nas raças Ideal e Corriedale, os coeficientes alométricos mostraram um desenvolvimento isogônico, semelhante ao do peso vivo. A partir destes dados, OLIVEIRA et al. (1996) concluíram que o crescimento dos cordeiros depende do genótipo. Portanto, o crescimento e o desenvolvimento dependem do genótipo, conseqüentemente, a uma mesma idade, o peso de abate ótimo varia de acordo com a raça (OSÓRIO et al., 1996).

Com respeito ao desenvolvimento da cabeça (tabela 1), observou-se que nas raças Romney 
Tabela 1 - Coeficientes de alometria (b), dos componentes do peso vivo em relação ao peso vivo.

\begin{tabular}{|c|c|c|c|c|}
\hline & & $\mathrm{b} \pm \mathrm{s}^{\mathrm{b}(1)}$ & $b \neq 1^{(2)}$ & $\mathrm{R}^{2}(\%)^{(3)}$ \\
\hline \multirow[t]{5}{*}{ Carcaça quente } & Merino & $1,323 \pm 0,144$ & $*$ & 91,33 \\
\hline & Ideal & $1,410 \pm 0,255$ & n.s. & 79,23 \\
\hline & Corriedale & $1,175 \pm 0,124$ & n.s. & 91,79 \\
\hline & Romney Marsh & $1,224 \pm 0,089$ & $*$ & 96,90 \\
\hline & Texel & $1,370 \pm 0,148$ & * & 91,45 \\
\hline \multirow[t]{5}{*}{ Cabeça } & Merino & $0,841 \pm 0,212$ & n.s. & 66,27 \\
\hline & Ideal & $0,932 \pm 0,279$ & n.s. & 58,27 \\
\hline & Corriedale & $0,947 \pm 0,097$ & n.s. & 92,32 \\
\hline & Romney Marsh & $0,587 \pm 0,102$ & $*$ & 84,55 \\
\hline & Texel & $0,582 \pm 0,184$ & * & 55,48 \\
\hline \multirow[t]{5}{*}{ Patas } & Merino & $0,995 \pm 0,409$ & n.s. & 42,51 \\
\hline & Ideal & $0,381 \pm 0,359$ & n.s. & 12,30 \\
\hline & Corriedale & $1,112 \pm 0,246$ & n.s. & 71,89 \\
\hline & Romney Marsh & $0,699 \pm 0,167$ & n.s. & 74,55 \\
\hline & Texel & $1,178 \pm 0,326$ & n.s. & 62,00 \\
\hline \multirow[t]{5}{*}{ Pelego } & Merino & $1,518 \pm 0,511$ & n.s. & 52,48 \\
\hline & Ideal & $0,833 \pm 0,497$ & n.s. & 25,96 \\
\hline & Corriedale & $1,203 \pm 0,308$ & n.s. & 65,58 \\
\hline & Romney Marsh & $0,819 \pm 0,104$ & n.s. & 91,11 \\
\hline & Texel & $1,295 \pm 0,323$ & n.s. & 66,84 \\
\hline
\end{tabular}

${ }^{1 .}$ erro padrão, ${ }^{2}$ significativo em nível de $5 \%$ de probabilidade, ${ }^{3 .}$ coeficiente de determinação.

Marsh e Texel este é heterogônico e precoce $(b<1)$. Por outro lado, os resultados apresentados pelas raças Merino Australiano, Ideal e Corriedale concordam com os encontrados por OSÓRIO et al. (1994a), que obtiveram coeficiente de alometria isogônico para cabeça em relação ao peso vivo.

Situação semelhante ocorreu com outros componentes do peso vivo como patas, pelego, vísceras brancas, coração, pulmões + traquéia e fígado (tabelas 1 e 2), que apresentaram desenvolvimento proporcional ao do peso vivo, em todos os genótipos estudados. Esses dados concordam com os encontrados por OSÓRIO et al. (1994a), para patas, pelego, vísceras brancas e coração, na raça Ideal.

Analisando os componentes do peso vivo (tabela 2), nas raças Ideal, Corriedale, Romney Marsh e Texel, o baço apresentou um desenvolvimento proporcional ao do peso vivo. $\mathrm{O}$ mesmo resultado foi encontrado em cordeiros Manchega (RUIZ DE HUIDOBRO \& CAÑEQUE, 1994). Na raça Merino Australiano, o desenvolvimento do baço mostrou-se tardio, discordando de LOPEZ SANCHEZ (1987), que encontrou desenvolvimento precoce para este componente.

Com relação à composição regional (tabela 3), observou-se que o pescoço apresentou um desenvolvimento precoce em relação à carcaça nas raças Corriedale e Romney Marsh. Nas raças Merino Australiano, Ideal e Texel, o desenvolvimento do pescoço foi semelhante ao da carcaça. Estudos realizados por ROQUE et al. (1997), comprovaram esse desenvolvimento isogônico da região do pescoço, para a raça Corriedale.

A região da paleta e a região do quarto, em todos os genótipos estudados, mostraram-se isogônicos em relação ao peso da carcaça fria. Quanto ao costilhar, a tabela 3 mostra que na raça Romney Marsh, houve um incremento de peso conforme o aumento de peso da carcaça fria. Sendo assim, o desenvolvimento do costilhar pode ser mais ou menos tardio ou, em alguns casos, até mesmo isogônico $(b=1)$. Corroboram com estes resultados, os obtidos por COLOMER \& ESPEJO (1973) e OSÓRIO et al. (1995). Portanto, para cada genótipo, ou grupo de genótipos, existe um peso ótimo de abate.

Sobre a composição tecidual da paleta (tabela 4), pode-se observar que o osso da paleta apresentou, na raça Romney Marsh, um desenvol-

Tabela 2 - Coeficientes de alometria (b), dos componentes do peso vivo (vísceras) em relação ao peso vivo.

\begin{tabular}{|c|c|c|c|c|}
\hline & & $\mathrm{b} \pm \mathrm{s}^{\mathrm{b}(1)}$ & $\mathrm{b} \neq 1^{(2)}$ & $\mathrm{R}^{2}(\%)^{(3)}$ \\
\hline \multirow[t]{5}{*}{ Vísceras brancas } & Merino & $0,394 \pm 0,406$ & n.s. & 10,53 \\
\hline & Ideal & $0,820 \pm 0,404$ & n.s. & 33,92 \\
\hline & Corriedale & $0,989 \pm 0,235$ & n.s. & 68,97 \\
\hline & Romney Marsh & $1,049 \pm 0,184$ & n.s. & 84,43 \\
\hline & Texel & $0,822 \pm 0,250$ & n.s. & 57,50 \\
\hline \multirow[t]{5}{*}{ Coração } & Merino & $1,000 \pm 0,611$ & n.s. & 25,11 \\
\hline & Ideal & $0,872 \pm 1,252$ & n.s. & 5,72 \\
\hline & Corriedale & $1,203 \pm 0,572$ & n.s. & 35,64 \\
\hline & Romney Marsh & $0,910 \pm 0,246$ & n.s. & 69,55 \\
\hline & Texel & $1,814 \pm 0,703$ & n.s. & 45,40 \\
\hline \multirow{5}{*}{$\begin{array}{c}\text { Pul- } \\
\text { mões+traquéia }\end{array}$} & Merino & $0,793 \pm 0,129$ & n.s. & 49,61 \\
\hline & Ideal & $0,961 \pm 0,799$ & n.s. & 15,31 \\
\hline & Corriedale & $0,596 \pm 0,526$ & n.s. & 13,86 \\
\hline & Romney Marsh & $0,611 \pm 0,505$ & n.s. & 19,63 \\
\hline & Texel & $1,057 \pm 0,749$ & n.s. & 19,92 \\
\hline \multirow[t]{5}{*}{ Baço } & Merino & $2,280 \pm 0,633$ & $*$ & 61,87 \\
\hline & Ideal & $2,358 \pm 1,180$ & n.s. & 33,28 \\
\hline & Corriedale & $1,552 \pm 0,627$ & n.s. & 43,34 \\
\hline & Romney Marsh & $1,229 \pm 0,434$ & n.s. & 57,22 \\
\hline & Texel & $1,886 \pm 1,196$ & n.s. & 23,71 \\
\hline \multirow[t]{5}{*}{ Fígado } & Merino & $1,443 \pm 0,339$ & n.s. & 69,31 \\
\hline & Ideal & $1,028 \pm 0,333$ & n.s. & 54,38 \\
\hline & Corriedale & $1,153 \pm 0,212$ & n.s. & 78,66 \\
\hline & Romney Marsh & $1,016 \pm 0,170$ & n.s. & 85,65 \\
\hline & Texel & $1,113 \pm 0,415$ & n.s. & 47,38 \\
\hline
\end{tabular}

\footnotetext{
${ }^{1 .}$ erro padrão, ${ }^{2}$ significativo em nível de $5 \%$ de probabilidade,

${ }^{3 .}$ coeficiente de determinação.
} 
Tabela 3 - Coeficientes de alometria (b), da composição regional em relação ao peso da carcaça fria.

\begin{tabular}{llccc}
\hline & & & & \\
& & $\mathrm{b} \pm \mathrm{s}^{\mathrm{b}(1)}$ & $\mathrm{b} \neq 1^{(2)}$ & $\mathrm{R}^{2}(\%)^{(3)}$ \\
\hline Pescoço & Merino & $0,655 \pm 0,573$ & n.s. & 14,05 \\
& Ideal & $0,581 \pm 0,584$ & n.s. & 11,01 \\
& Corriedale & $0,399 \pm 0,277$ & $*$ & 20,62 \\
& Romney Marsh & $0,559 \pm 0,131$ & $*$ & 75,21 \\
& Texel & $0,248 \pm 0,459$ & n.s. & 3,52 \\
Paleta & & & & \\
& Merino & $1,058 \pm 0,213$ & n.s. & 75,59 \\
& Ideal & $0,903 \pm 0,166$ & n.s. & 78,67 \\
& Corriedale & $0,926 \pm 0,040$ & n.s. & 98,50 \\
& Romney Marsh & $0,971 \pm 0,082$ & n.s. & 95,87 \\
& Texel & $1,123 \pm 0,098$ & n.s. & 94,27 \\
& & & & \\
Costilhar & Merino & $1,274 \pm 0,150$ & n.s. & 90,00 \\
& Ideal & $1,018 \pm 0,339$ & n.s. & 53,09 \\
& Corriedale & $1,019 \pm 0,095$ & n.s. & 93,55 \\
& Romney Marsh & $1,248 \pm 0,061$ & $*$ & 98,60 \\
& Texel & $1,338 \pm 0,171$ & n.s. & 88,44 \\
& & & & \\
Quarto & Merino & $0,705 \pm 0,209$ & n.s. & 58,79 \\
& Ideal & $0,974 \pm 0,150$ & n.s. & 84,11 \\
& Corriedale & $0,901 \pm 0,086$ & n.s. & 93,17 \\
& Romney Marsh & $0,982 \pm 0,073$ & n.s. & 96,83 \\
& Texel & $0,874 \pm 0,108$ & n.s. & 89,05 \\
& & & & \\
\hline
\end{tabular}

${ }^{1}$ erro padrão, ${ }^{2}$ significativo em nível de $5 \%$ de probabilidade,

3. coeficiente de determinação.

vimento precoce $(b<1)$. Esse resultado concorda com os encontrados por LOPEZ SANCHEZ (1987) e RUIZ DE HUIDOBRO \& CAÑEQUE (1994). Porém, nas outras raças estudadas, o desenvolvimento do osso da paleta mostrou-se proporcional ao aumento de peso da paleta. Resultado semelhante foi encontrado por ROQUE et al. (1997), trabalhando com 41 cordeiros Corriedale.

Nas raças Merino Australiano, Ideal, Corriedale e Romney Marsh, um incremento no peso da paleta resulta em um aumento na proporção de músculo desta peça, concordando com ROQUE et al. (1997). O inverso ocorreu na raça Texel, na qual um incremento no peso da paleta provocou uma diminuição da proporção de músculo da mesma. Resultado semelhante foi encontrado por RUIZ DE HUIDOBRO \& CAÑEQUE (1994), em cordeiros da raça Manchega.

Quanto à gordura da paleta, esperava-se um desenvolvimento tardio em relação ao peso da paleta (ROQUE et al., 1997). Entretanto, isso só ocorreu na raça Merino. Para os demais genótipos estudados, a gordura da paleta apresentou um desenvolvimento estatisticamente semelhante ao da região, concordando com os resultados obtidos por OSÓRIO et al. (1994b). Isso comprova que o desenvolvimento tecidual está relacionado com a raça.

$\mathrm{Na}$ tabela 4, verificou-se que o osso do quarto apresentou um desenvolvimento precoce em todos os genótipos estudados. A diminuição da proporção de osso em relação a este corte também foi encontrada por RUIZ DE HUIDOBRO \& CAÑEQUE (1994) e ROQUE $\boldsymbol{e}$ t al. (1997).

O músculo do quarto apresentou um desenvolvimento precoce nas raças Ideal, Corriedale, Romney Marsh e Texel. O coeficiente alométrico para os cordeiros Merinos Australianos (tabela 4) mostra que o músculo do quarto desenvolve-se a uma velocidade semelhante ao do peso do quarto, concordando com OSÓRIO et al. (1994b) e ROQUE et al. (1997).

A deposição de gordura do quarto, fator importante no acabamento das carcaças, mostrou-se tardia na raça Ideal. Porém, nos outros genótipos, a gordura depositou-se à mesma velocidade que no quarto, concordando com RUIZ DE HUIDOBRO \& CAÑEQUE (1994). Entretanto, este resultado discorda do obtido por ROQUE et al. (1997), que en-

Tabela 4 - Coeficientes de alometria (b), da composição tecidual da paleta e do quarto.

\begin{tabular}{|c|c|c|c|c|}
\hline & & $\mathrm{b} \pm \mathrm{s}^{\mathrm{b}(1)}$ & $\mathrm{b} \neq \mathrm{1}^{(2)}$ & $\mathrm{R}^{2}(\%)^{(3)}$ \\
\hline \multicolumn{5}{|l|}{ PALETA } \\
\hline \multirow[t]{5}{*}{ Osso } & Merino & $1,115 \pm 0,280$ & n.s. & 66,47 \\
\hline & Ideal & $0,525 \pm 0,408$ & n.s. & 17,16 \\
\hline & Corriedale & $1,004 \pm 0,213$ & n.s. & 73,49 \\
\hline & Romney Marsh & $0,546 \pm 0,151$ & $*$ & 68,53 \\
\hline & Texel & $0,776 \pm 0,155$ & n.s. & 75,74 \\
\hline \multirow[t]{5}{*}{ Músculo } & Merino & $1,312 \pm 0,097$ & $*$ & 95,84 \\
\hline & Ideal & $1,463 \pm 0,153$ & * & 91,92 \\
\hline & Corriedale & $1,442 \pm 0,094$ & * & 96,72 \\
\hline & Romney Marsh & $1,198 \pm 0,056$ & $*$ & 98,72 \\
\hline & Texel & $0,765 \pm 0,107$ & * & 86,43 \\
\hline \multirow[t]{5}{*}{ Gordura } & Merino & $5,173 \pm 1,275$ & $*$ & 67,30 \\
\hline & Ideal & $1,943 \pm 2,724$ & n.s. & 5,98 \\
\hline & Corriedale & $1,598 \pm 0,974$ & n.s. & 25,19 \\
\hline & Romney Marsh & $1,130 \pm 0,934$ & n.s. & 19,61 \\
\hline & Texel & $2,127 \pm 1,275$ & n.s. & 25,82 \\
\hline \multicolumn{5}{|c|}{ QUARTO } \\
\hline \multirow[t]{5}{*}{ Osso } & Merino & $0,310 \pm 0,189$ & $*$ & 25,16 \\
\hline & Ideal & $0,467 \pm 0,143$ & * & 57,14 \\
\hline & Corriedale & $0,554 \pm 0,098$ & * & 79,86 \\
\hline & Romney Marsh & $0,376 \pm 0,081$ & $*$ & 78,42 \\
\hline & Texel & $0,469 \pm 0,122$ & $*$ & 64,90 \\
\hline \multirow[t]{5}{*}{ Músculo } & Merino & $0,926 \pm 0,106$ & n.s. & 90,47 \\
\hline & Ideal & $0,674 \pm 0,047$ & $*$ & 96,25 \\
\hline & Corriedale & $0,742 \pm 0,063$ & * & 94,58 \\
\hline & Romney Marsh & $0,620 \pm 0,031$ & $*$ & 98,52 \\
\hline & Texel & $0,417 \pm 0,038$ & * & 93,80 \\
\hline \multirow[t]{5}{*}{ Gordura } & Merino & $1,735 \pm 1,074$ & n.s. & 24,59 \\
\hline & Ideal & $2,920 \pm 0,754$ & $*$ & 65,19 \\
\hline & Corriedale & $2,375 \pm 0,834$ & n.s. & 50,31 \\
\hline & Romney Marsh & $1,070 \pm 0,421$ & n.s. & 51,80 \\
\hline & Texel & $1,509 \pm 0,878$ & n.s. & 26,97 \\
\hline
\end{tabular}

1. erro padrão, ${ }^{2}$ significativo em nível de $5 \%$ de probabilidade, 3. coeficiente de determinação. 
contraram desenvolvimento tardio para a gordura em relação ao peso do quarto para a raça Corriedale.

Estudo realizado por OSÓRIO et $\boldsymbol{a l}$. (1998a), com a raça Corriedale, mostra um efeito significativo da idade de abate sobre as características in vivo, da carcaça e da carne e, recomendam os autores, considerar o peso vivo como um critério prático para abate dos cordeiros. Porém, cada raça terá seu peso de abate ótimo econômico (OSÓRIO et al., 1998b).

Observou-se uma grande variabilidade nos valores dos coeficientes de alometria encontrados em relação à bibliografia, talvez porque as distintas raças empregadas em cada trabalho seguem diferentes padrões de desenvolvimento, como apontou BUTTERFIELD (1988).

\section{CONCLUSÃO}

Baseando-se nas condições experimentais deste trabalho, podemos concluir que cada genótipo, ou grupo de genótipos, apresenta seu peso ótimo econômico de abate.

\section{REFERÊNCIAS BIBLIOGRÁFICAS}

BLACK, J.L. Producción Ovina. México: AGT, 1989. Crecimiento y desarrollo de corderos: p. 23-62.

BUTTERFIELD, R.M. The practical anatomy of beef suited to the Australian and export markets. In: RAS OF NSW BEEF SYMPOSIUM, 1968, Sydney. Proceedings... Sydney, Austrália: University of Sydney, 1968.

BUTTERFIELD, R.M. News concepts of sheep growth. Sydney: Sydney University, 1988. $168 \mathrm{p}$.

COLOMER, F., ESPEJO, M. Determinación del peso óptimo de sacrificio de los corderos procedentes del cruzamiento Manchega x Rasa Aragonesa en función del sexo. In: INIA SÉRIE PRODUCCIÓN ANIMAL, 1， 1971，Zaragoza, Anais... Zaragoza, 1971, p. 103-132.

COLOMER, F., ESPEJO, M. Influencia del peso al sacrificio y del sexo sobre las características de las canales de cordero de raza Rasa Aragonesa. An INIA, Serie Producción Animal, v. 4, p. 133-150, 1973.

HUXLEY, J.S. Problems of Relative Growth. Londres: Methuen, 1932

LOPEZ SANCHEZ, M. Calidad de la canal y la carne en los tipos lechal, ternasco y cordero de la raza Lacha y estudio de su desarrollo. Zaragoza, 1987. 465 p. Tese (Doutorado) Universidade de Zaragoza, 1987.

OLIVEIRA, N.M., OSÓRIO, J.C.S., MONTEIRO, E.M.
Produção de carne em ovinos de cinco genótipos. 1. Crescimento e desenvolvimento. Ciência Rural, Santa Maria, v. 26 , n. 3, p. $467-470,1996$

OSÓRIO, J.C., SIEWERDT, F., GUERREIRO, J.L. et al. Desenvolvimento relativo dos componentes do peso vivo em ovinos. In: REUNIÃO ANUAL DA SOCIEDADE BRASILEIRA DE ZOOTECNIA, 31, 1994, Maringá. Anais... Maringá, 1994a, p. 239.

OSÓRIO, J.C., SIEWERDT, F., GUERREIRO, J.L. et al. Coeficientes de alometria da composição tecidual da paleta e quarto em cordeiros Ideal e Ideal x Texel. In: REUNIÃO ANUAL DA SOCIEDADE BRASILEIRA DE ZOOTECNIA, 31, 1994, MARINGÁ. Anais... Maringá, 1994b, p. 241

OSÓRIO, J.C.S., SIEWERDT, F., OSÓRIO, M.T.M., et al. Desenvolvimento alométrico das regiões corporais em ovinos. Revista da Sociedade Brasileira de Zootecnia, Viçosa, v. 24, n. 2, p. 326-333, 1995

OSÓRIO, J.C.S., OLIVEIRA, N.M., NUNES, A.P. $\boldsymbol{e}$ t al. Produção de carne em ovinos de cinco genótipos. 3. Perdas e morfologia. Ciência Rural, Santa Maria, v. 26, n. 3, p. 477$481,1996$.

OSÓRIO, J.C., MARÍA, G.A., JARDIM, P.O. et al. Caracteres de crecimiento, sacrificio y canal en corderos de raza Corriedale criados en un sistema sostenible sobre pastos naturales de Rio Grande do Sul (Brasil). Información Técnica Económica Agraria (ITEA), Zaragoza-Espanha, v. 94, n. 1, p. 63-73, 1998a.

OSÓRIO, J.C.S., SAÑUDO, C., OSÓRIO, M.T. et al. Produção de carne ovina: alternativa para o Rio Grande do Sul. Pelotas: Editora e Gráfica Universitária - UFPel, 1998. 166 p.

PÁlSSON, H. Progress in Physiology of Farm Animals. Londres: Butterworths, 1955. v. 2. Conformation and body composition.

ROQUE, A.P., OSÓRIO, J.C.S., FARIA, H.V., et al. Desenvolvimento relativo dos componentes do peso vivo, da composicão regional e tecidual em cordeiros Corriedale. In: REUNIÃO ANUAL DA SOCIEDADE BRASILEIRA DE ZOOTECNIA, v.3, n.34, 1997, Juiz de Fora. Anais... Juiz de Fora, 1997, p. 296-298.

RUIZ DE HUIDOBRO, F., CAÑEQUE, V. Produccion de carne de corderos de raza Manchega. 5. Crecimiento relativo del quinto cuarto y de los tejidos y piezas de la canal. Investigacion Agraria: Produccion y Sanidad Animales, v. 9 , n. 2, p. $95-108,1994$

SAÑUDO, C. Calidad de la canal y de la carne en el ternasco aragonés. Zaragoza, 1980, 337 p. Tese (Doutorado) Universidad de Zaragoza, 1980.

SAS Institute Inc. SAS User's Guide: Statistics, Version 5. ed. Cary, NC: SAS Institute, 1985. 956 p.

THOMPSON, J.M., PARKS, J.R. Food intake, growth and mature size in Australian Merino and Dorset Horn sheep. Animal Production, v. 36, p. 471-479, 1983. 